\title{
PELATIHAN PEMBUATAN E-LEARNING SEBAGAI SARANA EVALUASI PEMBELAJARAN MATEMATIKA DI SMA MUHAMMADIYAH 1 JOMBANG
}

\author{
Siti Khoiruli Ummah \\ Pendidikan Matematika, FKIP Universitas Muhammadiyah Malang \\ khoiruliummah@umm.ac.id
}

DOI : 10.31604/j.martabe.v1i3.117-127

\begin{abstract}
Mentoring e-learning aimed to create innovation learning in particular means of evaluation of learning mathematics-based technology. E-Learning is one of the technological innovations combined with learning, one of the benefits purposed to evaluate learning using the internet. The method of the implementation of mentoring started from observation and permitting. The next stages were prepared the e-learning modules. Stage of implementation was done for four meetings. The final stage i.e. the analysis of implementation mentoring. The results of the training participants, i.e. in this case the teacher, already have e-learning account through Google Classroom or Edmodo. In addition, teachers could create and upload the instrument of learning evaluation in this assignment of unbounded time using separate files as well as the quiz online. Teachers could also manipulate the score by way of export grade from Edmodo in the form file formats such as Excel and calculate an average, specify the maximum value or the minimum value. Learning evaluation of the instrument, in this case, a math problem, have been able to be uploaded directly by the teacher using the equation to write mathematics. In this case, the teacher uses the format of the equation in the form of LaTeX.
\end{abstract}

Key words: Training of e-learning, Edmodo, Google classroom, LaTeX, Evaluation of Mathematics Learning.

\begin{abstract}
Abstrak
Pendampingan dan pelatihan pembuatan e-learning bertujuan untuk menciptakan inovasi pembelajaran khususnya sarana evaluasi pembelajaran matematika berbasis teknologi. E-Learning merupakan salah satu inovasi teknologi yang dikombinasikan dengan pembelajaran, salah satunya diamanfaatkan untuk mengevaluasi pembelajaran melalui internet. Metode pelaksanaan pendampingan dan pelatihan diawali dari observasi dan perijinan. Tahapan selanjutnya yaitu penyusunan modul e-learning. Tahap pelaksanaan dilakukan selama empat pertemuan. Tahap akhir yaitu analisis keterlaksanaan pendampingan dan pelatihan. Hasil pelatihan yaitu peserta pelatihan, dalam hal ini guru, sudah mempunyai akun e-learning melalui google classroom maupun edmodo. Selain itu, guru dapat membuat dan mengupload instrument evaluasi pembelajaran dalam hal ini penugasan berbatas waktu menggunakan file terpisah maupun kuis secara online. Guru juga dapat mengolah skor dengan cara mengekspor grade pada edmodo dalam bentuk file berformat Excel dan menghitung rata-rata, menentukan nilai maksimum maupun nilai minimum. Instrumen evaluasi pembelajaran,
\end{abstract}


dalam hal ini soal matematika, telah dapat diupload secara langsung oleh guru menggunakan equation untuk menuliskan matematika. Dalam hal ini, guru menggunakan format equation berupa LaTeX.

Kata kunci: Pelatihan e-learning, Edmodo, Google classroom, LaTeX, Evaluasi Pembelajarn Matematika.

\section{PENDAHULUAN}

Pemanfaatan teknologi dalam pembelajaran matematika tidak selalu berupa media pembelajaran. Teknologi berperan penting dalam peningkatan kualitas pembelajaran tidak hanya sebagai sumber belajar dan media pembelajaran melainkan sebagai penunjang guru untuk merencanakan dan memberikan evaluasi kepada siswa. Selama ini, teknologi komputasi telah popular disebut dengan istilah ICT (Information and Communication Technology) sejak Tahun 1992 dimana sebelumnya disebut dengan istilah IT (Information Technology) pada Tahun 1980-an (Thakur, 2017). ICT atau yang lebih dikenal dengan Teknologi Informasi dan Komunikasi, mencakup jaringan internet, sarana dan prasarana telekomunikasi, sarana dan prasarana teknologi, media, penyiaran, pusat dokumentasi dan perpustakaan, penyedia informasi yang komersial, layanan informasi berbasis internet, dan aktivitas komunikasi dan informasi lainnya (Schools, Of, \& Development, n.d.). Produk dari ICT yang dapat dikaitkan dengan pendidikan sangat beragam. Contoh produk yang digunakan dalam pendidikan antara lain: (1) telekonferensi, (2) email, (3) penyiaran radio, (4) tayangan $\mathrm{TV},(5)$ konsultasi interaktif melalui radio, (6) kaset pita, (7) flashdisk, (8) harddisk eksternal, (9) microSD, dan lain-lain (Technology, 2012).

ICT mempunyai peranan penting dalam pendidikan yaitu sebagai inovasi, akselerasi, motivasi siswa, dan bantuan kepada sekolah agar menjadi maju (Matthew dkk, 2015). Selama ini, penggunaan ICT dalam pendidikan terbatas pada peranannya sebagai sumber informasi atau sumber belajar, media pembelajaran atau yang lebih sering digunakan yaitu power point, dan pengiriman tugas melalui email. Sebagai seorang guru sudah seharusnya meningkatkan kualitas pembelajarannya terutama perencanaan pembelajaran (Hadullo dkk, 2017). ICT mempunyai hubungan erat dengan siswa terutama melalui penggunaan handphone. Kenyataannya, seringkali terlihat siswa mengoperasikan handphone saat pembelajaran berlangsung. Siswa seringkali menggunakan handphone untuk berkomunikasi melalui social media. Selain itu, siswa juga seringkali menggunakan handphone atau lebih khususnya pada pencarian khusus menggunakan Google untuk menyelesaikan tugas Yengin dkk, 2010. Seringnya siswa yang mengakses internet melalui handphone seharusnya dapat diintegrasikan dalam pembelajaran agar dapat meningkatkan dan mengembangkan lingkungan pembelajaran yang mendukung aktivitas belajar siswa. Agar integrasi internet dengan pembelajaran dapat berjalan efektif, maka guru harus dapat terlibat dalam pembelajaran yang berbasis teknologi (Abou dkk, 2014).

Keterlibatan guru dalam pembelajaran berbasis teknologi antara lain: (1) mengenalkan penggunaan ICT dalam bentuk internet kepada siswa, (2) 
Siti Khoiruli Ummah. Pelatihan Pembuatan E-Learning Sebagai ...

mengontrol penggunaan internet pada siswa selama pembelajaran, dan (3) menyiapkan siswa untuk generasi berbasis ICT untuk penunjang karirnya di masa yang akan datang, dan memungkinkan siswa bertukar data satu sama lain secara praktis dan efisien (Hassan dkk, 2012). Salah satu produk ICT yang paling popular yaitu elearning. E-learning dapat dimanfaatkan sebagai sarana komunikasi efektif pada pembelajaran jarak jauh dalam bentuk video conference (Roberts, 2009). Manfaat e-learning selanjutnya yaitu sebagai bantuan siswa untuk memahami pembelajaran, terfokus pada materi dan untuk mengkaji dan mereview pembelajaran yang telah disampaikan sebelumnya serta dapat memotivasi siswa belajar dan memberikan reaksi positif terhadap pembelajaran matematika.

Pemanfaatan e-learning di SMA Muhammadiyah 1 Jombang belum pernah ada. Hal ini dikarenakan guru tidak sempat dalam membuat berbagai media yang akan dinpitkan pada elearning yang dimiliki. Pelatihan elearning juga belum pernah dilaksanakan di sekolah tersebut. Hal ini sangat disayangkan karena kualitas jaringan internet di sekolah tersebut sangat baik. Di sekolah tersebut, siswa diperbolehkan membawa handphone ke sekolah tetapi tidak boleh diakses selama pembelajaran. Hal ini juga dijadikan alasan mengapa e-learning perlu didalami oleh guru agar siswa dapat memanfaatkan handphone sebagai saran penunjang pembelajaran khususnya matematika. Selama ini, evaluasi pembelajaran matematika di sekolah dilakukan secara manual yaitu pemberian soal post-test yang ditulis di papan tulis, melalui pemberian Lembar Kerja Siswa, pemberian lembar soal Ujian Tengah Semester dan lembar soal Ujian Akhir Semester. Hal ini dikarenakan, guru kesulitan dalam penulisan equation sebagai rumus matematika (Kurniasih dkk, 2016).

Evaluasi pembelajaran merupakan substansi esensial dalam suatu kurikulum. Evaluasi pembelajaran merupakan pengumpulan, analisis, dan diskusi tentang bukti dari sumber yang relevan, akurat tentang kualitas, efektivitas, dan dampak dari adanya suatu kebijakan. Evaluasi pembelajaran mempunyai ciri khusus daripada pengukuran dan asesmen. Evaluasi pembelajaran mengharuskan adanya timbal-balik terhadap hasil belajar siswa (Adzobu, 2014).

Pemanfaatan teknologi dapat digunakan sebagai penunjang pembelajaran, khususnya evaluasi pembelajaran. Beberapa penelitian, $e$ assessment dan e-evaluation dalam pembelajaran sangat mendukung dan memotivasi siswa dalam belajar. Selain itu, pelaksanaan UN yang menggunakan computer, mengharuskan sekolah untuk membiasakan siswa melakukan evaluasi dengan menggunakan computer. SMA Muhammadiyah $1 \quad$ Malang memanfaatkan ujian melalui computer hanya pada saat tryout di laboratorium computer. Padahal, pelaksanaan tes, kuis, pengumpulan tugas tidak terbatas pada pemanfaatan email dan aplikasi computer seperti halnya UN. Pengerjaan soal, pengumpulan tugas, kuis, dalam bentuk uraian maupun pilihan ganda dapat dilakukan dengan memanfaatkan aplikasi pada handphone. Aplikasi tersebut dapat dikategorikan pula sebagai e-learning (Ekici, 2017).

Salah satu contoh aplikasi elearning berbasis Android dan Windows yaitu Edmodo. Aplikasi Edmodo dapat digunakan sebagai evaluasi pembelajaran dalam bentuk penugasan yang mengharuskan siswa upload file dengan batas waktu pengumpulan 
tertentu, kuis dengan waktu tertentu, Tanya-jawab secara langsung, dan kuisioner (Al-Said, 2015 dan Bobo, 2018; Slip, n.d.). Aplikasi Edmodo juga dapat menyimpan berbagai file seperti halnya perpustakaan online (Ali, 2015 dan Batsila dkk, 2014). Kelebihan Edmodo selanjutnya yaitu penskoran dapat langsung didownload oleh guru dalam bentuk Excel (Nasrullah dkk, 2017). Hal ini akan memudahkan guru merekap nilai.

Pentingnya pemanfaatan teknologi pada pembelajaran dalam penyediaan aplikasi evaluasi pembelajaran mendorong penulis untuk melatih dan mendampingi guru di SMA Muhammadiyah 1 Jombang untuk membuat e-learning. Pelatihan dan pendampingan pembuatan e-learning akan difokuskan pada aplikasi Edmodo dan akan diujicobakan kepada siswa.

\section{METODE PELAKSANAAN}

Metode yang ditawarkan untuk menyelesaikan persoalan mitra yaitu memberikan pelatihan dan pendampingan pembuatan e-learning bagi guru SMA Muhammadiyah 1 Jombang. Pelatihan dan pendampingan pembuatan e-learning akan berlangsung selama empat kali pertemuan sampai terciptanya e-learning dalam bentuk aplikasi Edmodo pada setiap guru.

Tahap awal dari kegiatan pengabdian yaitu observasi ke sekolah untuk melakukan analisis awal. Analisis awal dilakukan untuk mencari tahu tentang kendala pembelajaran matematika di sekolah terkait bentuk evaluasinya. Selain itu, observasi tentang ketersediaan layanan internet dan gadget pada guru dan siswa.

Tabel 1: Kegiatan Pelatihan Edmodo

\begin{tabular}{|c|c|c|c|}
\hline Kegiatan & \multirow{2}{*}{\multicolumn{2}{|c|}{$\begin{array}{l}\text { Waktu Pelaksanaan } \\
\text { Minggu III Bulan } \\
\text { Desember } 2017\end{array}$}} & Keterlibatan Mitra \\
\hline Observasi & & & $\begin{array}{l}\text { Menyediakan informasi tentang permasalahan, sarana } \\
\text { dan prasarana, dan perijinan }\end{array}$ \\
\hline $\begin{array}{l}\text { Pembuatan dan } \\
\text { pengajuan } \\
\text { proposal }\end{array}$ & $\begin{array}{lc}\text { Minggu } & \text { IV } \\
\text { Desember } & 2017\end{array}$ & Bulan & Penandatanganan surat kesediaan mitra \\
\hline $\begin{array}{l}\text { Pembuatan } \\
\text { instrumen }\end{array}$ & $\begin{array}{l}\text { Minggu III } \\
\text { Januari } 2018\end{array}$ & Bulan & Pembuatan handout pelatihan Edmodo \\
\hline $\begin{array}{l}\text { Sosialisasi } \\
\text { Awal }\end{array}$ & $\begin{array}{l}\text { Minggu III } \\
\text { Februari } 2018\end{array}$ & Bulan & $\begin{array}{l}\text { Guru mengikuti kegiatan orientasi awal tentang } \\
\text { pelaksanaan pelatihan dan } \\
\text { pendampingan, materi pelatihan, dan tugas akhir } \\
\text { yang } \\
\text { harus dibuat }\end{array}$ \\
\hline $\begin{array}{l}\text { Pelatihan } \\
\text { Edmodo I }\end{array}$ & $\begin{array}{l}\text { Minggu IV } \\
\text { Februari } 2018\end{array}$ & Bulan & $\begin{array}{l}\text { Peserta pelatihan mendaftar ke Edmodo dan } \\
\text { mengikuti penjelasan tentang fitur pada Edmodo }\end{array}$ \\
\hline $\begin{array}{l}\text { Pelatihan } \\
\text { Edmodo II }\end{array}$ & $\begin{array}{l}\text { Minggu I Bulan } \\
2018\end{array}$ & Maret & $\begin{array}{l}\text { Guru membuat materi dan soal matematika } \\
\text { memanfaatkan Math Equation }\end{array}$ \\
\hline $\begin{array}{l}\text { Pelatihan } \\
\text { Edmodo III }\end{array}$ & $\begin{array}{l}\text { Minggu II Bulan } \\
2018\end{array}$ & Maret & Guru meng-upload sumber belajar ke Edmodo \\
\hline $\begin{array}{l}\text { Pelatihan } \\
\text { Edmodo IV }\end{array}$ & $\begin{array}{l}\text { Minggu III Bulan } \\
2018\end{array}$ & Maret & $\begin{array}{l}\text { Guru membuat kuis dan tugas berbatas waktu melalui } \\
\text { Edmodo }\end{array}$ \\
\hline Evaluasi akhir & $\begin{array}{l}\text { Minggu IV Bulan } \\
2018\end{array}$ & Maret & $\begin{array}{l}\text { Mitra mengumpulkan tugas dan Tanya-jawab tentang } \\
\text { kesulitan penggunaan Edmodo }\end{array}$ \\
\hline
\end{tabular}


Siti Khoiruli Ummah. Pelatihan Pembuatan E-Learning Sebagai ...

Langkah selanjutnya yaitu pembuatan instrument pelatihan. Instrumen pelatihan berupa handout dengan mengacu pada literature yang berkaitan dengan e-learning melalui Edmodo. Literatur yang dirujuk pada kegiatan studi kepustakaan yaitu tentang elearning dan macam-macamnya, penggunaan edmodo, dan macammacam evaluasi pembelajaran.

Selanjutnya dilakukan sosialisasi awal yang dilakukan sebanyak satu pertemuan dengan materi pengenalan eleraning dan macam-macamnya. Pada kegiatan ini, guru diperkenalkan tentang penggunaan internet yang diintegrasikan dalam pembelajaran melalui handphone. Selain itu, kegiatan sosialisasi juga digunakan untuk mengidentifikasi ada atau tidaknya email pada guru. Apabila belum punya, maka guru didampingi untuk membuat email terlebih dahulu. Pelatihan Edmodo dilakukan sebanyak empat pertemuan dengan materi pelatihan sebagai berikut:

a. Pembuatan akun Edmodo untuk guru dan pengenalan fitur-fitur Edmodo.

b. Penulisan materi atau bahan ajar dengan memanfaatkan Math Equation dan Graphmatica dan diupload pada fitur EdmodoLibrary.

c. Pembuatan tugas essay berbatas waktu.

d. Pembuatan Kuis dengan durasi waktu tertentu.

e. Pembuatan Evaluasi Pembelajaran melalui Edmodo.

Pembuatan evaluasi pembelajaran melalui Edmodo dalam bentuk tugas essay dan pilihan ganda pada subbab tertentu matematika. Evaluasi pembelajaran akan diupload atau dibuat langsung dengan durasi waktu tertentu. Selain itu, evaluasi akan memanfaatkan aplikasi lain yaitu Graphmatica dan penggunaan Math equation untuk penulisan rumus matematika.

\section{HASIL DAN PEMBAHASAN}

Observasi dilaksanakan di SMA Muhammadiyah 1 Jombang. Observasi dilakukan dengan cara melihat fasilitas dan mewawancarai wakil kepala sekolah bidang kurikulum. Hasil observasi difokuskan pada kondisi laboratorium da jaringan internet di sekolah. Adapun hasil observasi sebagai berikut:

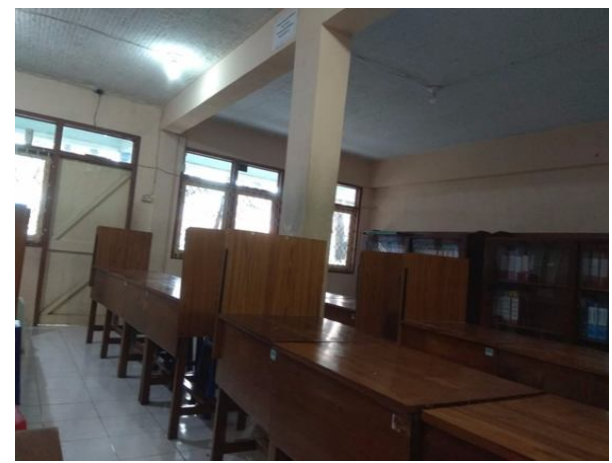

\section{Gambar 1: Laboratorium Bahasa SMA Muhammadiyah 1 Jombang}

Sesuai Gambar 1, laboratorium yang akan digunakan yaitu laboratorium bahasa. Hal ini dikarenakan, laboratorium komputer masih dalam tahap perbaikan sehingga jaringan internet lemah. Di laboratorium bahasa ini, dapat menampung 30 orang dengan meja individu. Selain itu, terdapat kabel LAN untuk jaringan internet serta ruangan ber-AC. LCD dan proyektor juga tersedia dan dapat berfungsi dengan baik di ruangan ini.

Jumlah guru yang akan mengikuti pelatihan ini adalah sebagai berikut: 
Tabel 2: Jumlah Guru Peserta
Pelatihan

\begin{tabular}{cc}
\hline $\begin{array}{c}\text { Guru Mata } \\
\text { Pelajaran }\end{array}$ & $\begin{array}{c}\text { Jumlah } \\
\text { Guru }\end{array}$ \\
\hline Matematika & 6 \\
Fisika & 4 \\
Kimia & 3 \\
Biologi & 4 \\
\hline
\end{tabular}

Guru yang diikutsertakan yaitu guru matematika dan IPA yang memerlukan penulisan rumus dan mengajar kelas XII. Hal ini dimaksudkan agar guru dapat terbiasa mengoperasikan komputer dan internet.

Adapun permasalahan yang dihadapi mitra yaitu kurangnya kegiatan guru di sekolah sehingga guru lebih banyak menghabiskan waktu untuk mengobrol, streaming youtube, atau berjalan-jalan. Guru juga belum pernah mengikuti bakan membuat serta memanfaatkan e-learning dalam pembelajaran. Wakil kepala sekolah menyampaikan bahwa masih banyak guru yang belum terbiasa menggunakan komputer dan internet dalam pembelajaran. Guru juga masih belum terbiasa menulis matematika menggunakan Equation. Kegiatan pengembangan skill perlu diadakan di SMA Muhammadiyah 1 Jombang agar guru semakin melek teknologi dan berwawasan luas.

Tahap selanjutnya yaitu perijinan. Perijinan dilakukan dengan membicarakan kesediaan mitra menjadi subyek pelatihan e-learning.

Penandatangan surat kesediaan mitra dilakukan secara informal dengan berdiskusi terlebih dahulu terkait jadwal pelaksanaan pelatihannya. Wakil kepala sekolah bersedia menyiapkan tempat dan fasilitas sebagai pelatihan elearning. Adapun surat kesediaan mitra ditandatangani di atas materai.
Sosialisasi awal seharusnya dilakukan bersama dengan guru calon peserta pelatihan e-learning. Akan tetapi, pada saat yang bertepatan dengan adanya rapat, sosialisasi awal hanya dilaksanakan dengan wakil kepala sekolah bidang kurikulum yang sekaligus sebagai guru matematika. Adapun materi sosialisasi yaitu:

a. Macam-macam e-learning

b. E-learning yang akan digunakan untuk pelatihan

c. Tanya-jawab tentang aplikasi LaTeX

d. Fasilitas penunjang untuk pelatihan yang diusulkan mitra (modul)

Pembuatan modul E-Learning membutuhkan waktu yang cukup lama. Hal ini dikarenakan, materi e-learning yang disampaikan masih belum pasti. Edmodo pada akhirnya terpilih sebagai jenis e-learning yang akan digunakan selama pelatihan. Pembuatan modul Edmodo dilakukan secara sistematis sesuai dengan fitur-fitur yang disediakan oleh Edmodo. Adapun materi modul sebagai berikut:

Modul 1: Pembuatan Akun Email

Modul 2: Pengenalan Edmodo

Modul 3: Pembuatan Akun Edmodo

Modul 4: Pengorganisasian Edmodo oleh Guru

Modul 5: Pembuatan Soal di Edmodo Dengan Melibatkan Rumus

Modul Edmodo kemudian ditambahkan materi tentang penulisan rumus pada edmodo menggunakan LaTeX dan pengoperasian aplikasi Edmodo melalui smartphone. Adapun wujud modul Edmodo sebagai berikut:

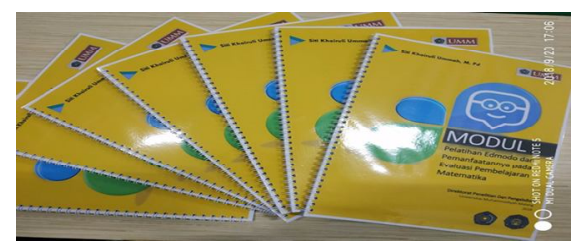

Gambar 2: Modul Pelatihan Edmodo 
Siti Khoiruli Ummah. Pelatihan Pembuatan E-Learning Sebagai ...

Modul yang dibuat mempunyai karakteristik sebagai berikut:

a. Dicetak secara portrait pada ukuran kertas A4 dengan berat 80 gram

b. Margin Right $3 \mathrm{~cm}$, Left $4 \mathrm{~cm}$, Top $4 \mathrm{~cm}$, dan Bottom $4 \mathrm{~cm}$

c. Cover didesain oleh mahasiswa yang membantu pengabdian dosen menggunakan Microsoft Word dan dicetak di kertas A4

d. Modul dijilid spiral dengan cover yang telah dilaminasi

Pelatihan Edmodo yang

dilaksanakan secara bertahap dengan tatap muka sebanyak empat kali. Adapun rincian pelatihan setiap tatap muka adalah sebagai berikut:

Pertemuan I

Pertemuan I berlangsung dalam waktu 120 menit di SMA Muhammadiyah 1 Jombang pada Hari Sabtu, Tanggal 4 Agustus 2018 pukul 10.00 - 12.00. Pelatihan berlangsung efektif dan lancar. Materi pelatihan yaitu optimalisasi akun email menggunakan domain gmail.com. Optimalisasi yang dilakukan yaitu menggunakan fitur-fitur yang terdapat pada gmail. Fitur tersebut antara lain: google classroom, form, dan hangouts. Fitur tersebut dilatihkan dengan tujuan agar guru memiliki wawasan tentang elearning yang paling mudah digunakan. Adapun hasil pelatihan dari materi optimalisasi fitur gmail antara lain:

a. Guru sudah mempunyai akun gmail. Selama ini, akun gmail dimanfaatkan untuk login pada smartphone, mendaftar di online shop maupun aplikasi yang memerlukan login email

b. Guru belum mengetahui adanya fitur-fitur pada gmail yang dapat dimanfaatkan pada pembelajaran

c. Guru dapat membuat kelas melalui google classroom dan telah mencoba untuk dioperasikan dengan peserta pelatihan lainnya

d. Guru dapat membuat form sederhana dengan isian nama dan hobi saja, belum ada yang mencoba membuat radiobutton, checklist, hanya menggunakan deskripsi

e. Guru mencoba menggunakan hangouts tetapi terkendala jaringan internet yang lambat sehingga materi hangouts belum optimal

Bukti pelatihan I dapat dilihat pada gambar berikut:

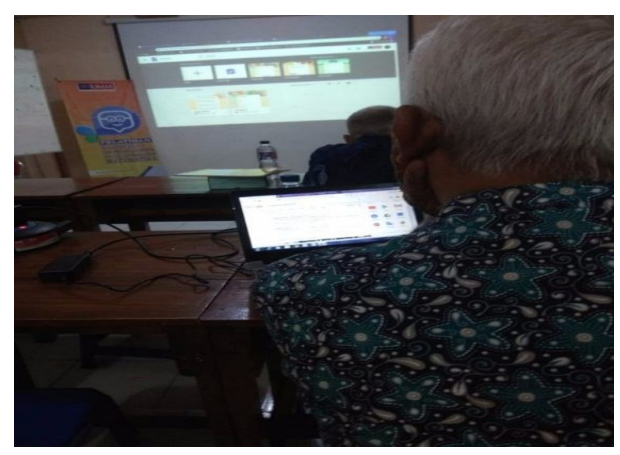

Gambar 3: Pelatihan I Optimalisasi Akun Email

\section{Pertemuan II}

$\begin{array}{ccc} & \text { Pertemuan ini membahas } \\ \text { tentang pengenalan } & \text { Edmodo. }\end{array}$

Pengenalan Edmodo berlangsung selama 150 menit dan dilaksanakan Tanggal 11 Agustus 2018 Pukul 10.00. Peserta pelatihan berjumlah 5 orang dan berlangsung sangat kondusif. Peserta pelatihan sangat antusias mengikuti pelatihan mengingat Edmodo baru pertama kali dikenal dan dioperasikan. Pengenalan Edmodo diawali dari fitur Edmodo yang bisa diakses oleh guru, siswa, atau orang tua. Pada pelatihan ini, guru diminta untuk registrasi sebagai guru. Setelah melakukan registrasi atau pembuatan akun, guru dikenalkan dengan fitur-fitur Edmodo. Adapun materi pengenalan Edmodo antara lain:

a. Cara membuat akun Edmodo 
b. Penjelasan fitur-fitur Edmodo

c. Pembuatan Kelas Edmodo

d. Join Class antar peserta pelatihan

e. Pengelolaan Library pada Edmodo

f. Upload file melalui Edmodo

Pelatihan materi tersebut mempunyai kendala diantaranya guru salah membuat akun siswa sehingga tidak bisa membuat kelas Edmodo. Selain itu, ada satu guru yang lupa password email yang dibuatnya sehingga tidak bisa mengkonfirmasi pembuatan akun Edmodo melalui Inbox email. Hasil pelatihan II ini antara lain:

a. Guru mempunyai akun Edmodo sebagai guru

b. Guru membuat kelas sesuai dengan kelas matematika yang diampu

c. Kelas yang bisa dibuat dan digunakan masih berjumlah satu untuk setiap orang

d. Guru telah mengupload file ke library di Edmodo dan membuat folder sesuai dengan materi pelajaran.

Hasil pelatihan tersebut mendapat respon positif dari peserta. Peserta menyampaikan secara langsung bahwa tertarik mempelajari lebih lanjut tentang Edmodo. Adapun bukti dokumentasi pelatihan Edmodo dapat dilihat pada Gambar 3.

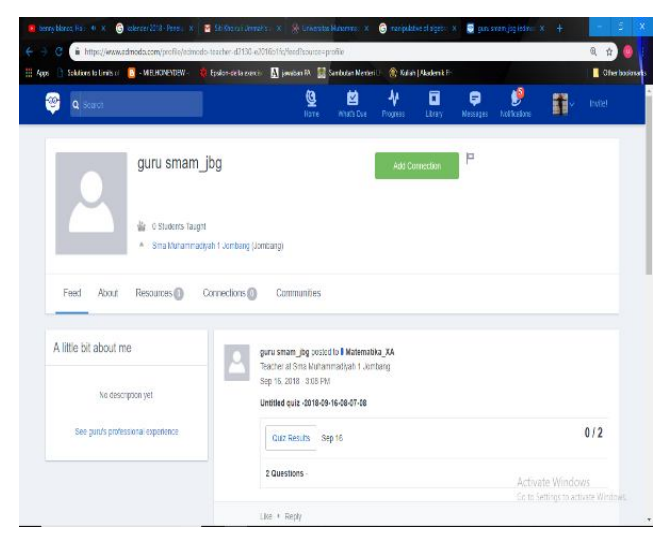

Gambar 4: Akun Edmodo Guru SMA Muhammadiyah 1 Jombang

\section{Pertemuan III}

Pertemuan selanjutnya membahas tentang pembuatan kuis dan penugasan online melalui Edmodo. Pelatihan dilaksanakan Tanggal 18 Agustus 2018 pukul 10.00. Peserta pelatihan berjumlah 5 orang. Pelatihan kali ini peserta diharapkan mampu untuk membuat soal secara online dan saling bertukar kuis dengan peserta pelatihan lainnya. Adapun secara detail, materi pelatihan sebagai berikut:

a. Pembuatan tugas berbatas waktu

b. Pembuatan kuis berupa pilihan ganda maupun benar-salah

c. Pelatihan menulis matematika menggunakan LaTeX

Peserta mendapat kesulitan ketika belajar tentang menulis matematika menggunakan Microsoft Word. Hal ini dikarenakan banyak sekali simbol dan urutan penulisan pada Equation. Peserta perlu ketelitian dan ketelatenan dalam pembuatan simbol matematika. Setelah pelatihan berlangsung, hasil yang diperoleh sebagai berikut:

a. Guru membuat penugasan dengan berbatas waktu

b. Penugasan yang diupload berupa file dengan format pdf berupa soalsoal olimpiade

c. Peserta saling mengerjakan dan mengupload jawaban dari penugasan yang diberikan peserta lainnya

d. Peserta membuat kuis berupa pilihan ganda dengan 4 pilihan jawaban

e. Peserta saling turned in kuis yang telah dibuat

Kuis dan penugasan yang dibuat tidak terlalu banyak nomornya. Hal ini dikarenakan adanya keterbatasan waktu dan hambatan ketika menulis equation. Bukti kuis dan penugasan yang dibuat 
Siti Khoiruli Ummah. Pelatihan Pembuatan E-Learning Sebagai ...

dapat dilihat pada Gambar 4 tentang kuis pilihan ganda.

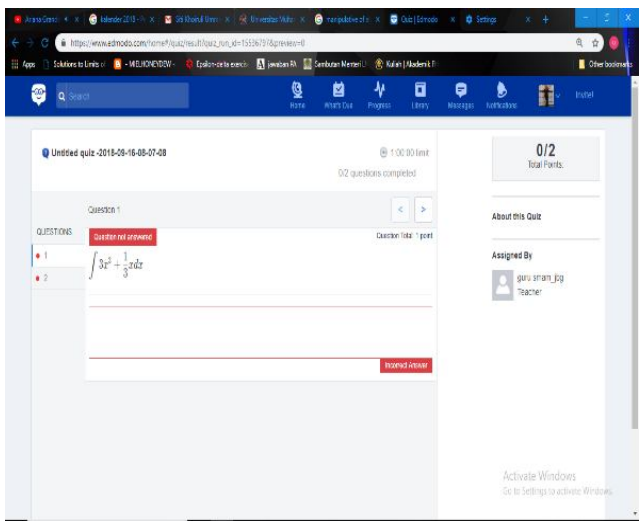

Gambar 4: Kuis yang dibuat Peserta Pelatihan

Pertemuan IV

Pelatihan keempat dilaksanakan Tanggal 27 Agustus 2018 pukul 10.00. Pelatihan ini diikuti oleh 5 guru SMAM 1 Jombang. Pertemuan terakhir akan membahas pengelolaan skor dari hasil kuis dan penugasan melalui Edmodo. Peserta pelatihan diharapkan dapat mengolah skor melalui ekspor data ke Excel. Materi pertemuan antara lain:

a. Menganalisis peserta lain yang mengikuti kuis yang telah dibuat

b. Mengekspor nilai dari Edmodo ke Excel

c. Mengolah nilai dalam bentuk Excel

Beberapa kendala yang dihadapi peserta pelatihan antara lain peserta masih kebingungan melihat hasil skor kuis pada turned in. Selain itu, saat mengolah data melalui Excel, peserta kebanyakan lupa dengan formula pada Excel untuk mencari rata-rata menggunakan Average dan skor maksimum serta minimum. Hasil pelatihan pada pertemuan keempat antara lain:

a. Guru telah dapat menganalisis keikutsertaan peserta lain pada kuis yang dibuat menggunakan turned- in kemudian menganalisis jawaban peserta setiap nomor

b. Guru telah dapat menyimpan file Excel hasil ekspor data kuis

c. Guru dapat mengelola skor hasil kuis, misalnya mencari skor tertinggi, terendah, rata-rata, maupun membuat rata-rata dari beberapa skor.

Contoh bukti dari analisis hasil kuis dapat dilihat pada Gambar 5

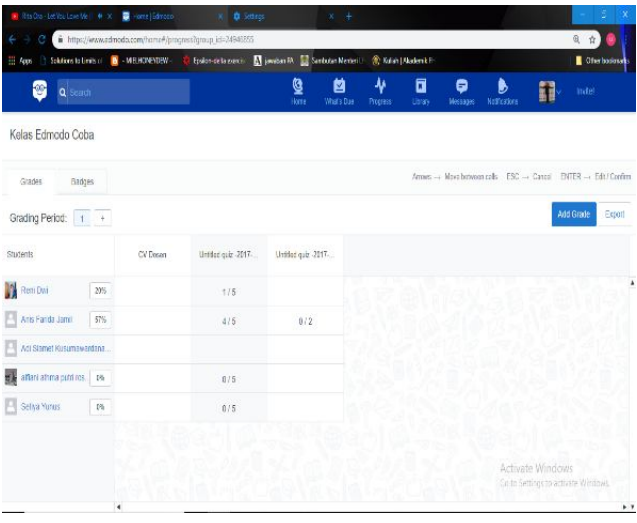

Gambar 5: Gradebook

Pelatihan Edmodo di SMA Muhammadiyah 1 Jombang mempunyai respon positif bagi peserta. Hal ini disampaikan langsung oleh peserta pelatihan. Adapun hal-hal yang menjadikan pelatihan Edmodo mempunyai respon positif bagi guru yaitu Edmodo sangat mudah digunakan. Hal ini didasarkan pada fitur-fitur Edmodo tergambar secara jelas pada icon dan menubar. Hal ini sejalan dengan penelitian (Kurniasih et al., 2016) yang menyatakan bahwa pembelajaran menggunakan bantuan Edmodo sangat mudah untuk diaplikasikan dan digunakan oleh guru dan siswa. Selain itu, fitur-fitur Edmodo sangat mendukung dan mempermudah guru melakukan evaluasi pembelajaran. Hal ini juga sejalan dengan penelitian (Batsila et al., 2014; Pgri, n.d.; Slip, n.d.) yang menyatakan bahwa Edmodo melalui fitur ekspor data dari 
Gradebook memudahkan guru mengelola skor menggunakan Excel.

Evaluasi pembelajaran matematika menjadi sangat mudah digunakan karena Edmodo telah terintegrasi dengan aplikasi MaTex sehingga memudahkan guru menulis matematika atau rumus matematika dnegan sangat mudah. Hal ini sejalan dengan penelitian (Ekici, 2017) yang menyatakan bahwa menulis matematika dapat terintegrasi secara langsung melalui Edmodo dengan bantuan LaTeX. Kemudahan evaluasi pembelajaran juga diperoleh dari pengalaman guru mengoperasikan Edmodo. Hal ini sejalan dengan penelitian (Al-Said, 2015; Ali, 2015; Batsila et al., 2014; Kurniasih et al., 2016) yang menyatakan bahwa pengelolaan Edmodo sangat praktis karena dapat diakses melalui gadget oleh siswa, guru, orang tua dimanapun dan kapanpun.

\section{SIMPULAN}

Hasil pelatihan yaitu peserta pelatihan, dalam hal ini guru, sudah mempunyai akun e-learning melalui google classroom maupun edmodo. Selain itu, guru dapat membuat dan mengupload instrument evaluasi pembelajaran dalam hal ini penugasan berbatas waktu menggunakan file terpisah maupun kuis secara online. Guru juga dapat mengolah skor dengan cara mengekspor grade pada edmodo dalam bentuk file berformat Excel dan menghitung rata-rata, menentukan nilai maksimum maupun nilai minimum. Instrumen evaluasi pembelajaran, dalam hal ini soal matematika, telah dapat diupload secara langsung oleh guru menggunakan equation untuk menuliskan matematika. Dalam hal ini, guru menggunakan format equation berupa LaTeX.

Pelatihan Edmodo berperan penting dalam mewujudkan pembelajaran yang praktis, efektif, dan berbasis teknologi. Peran tersebut dapat berupa kepraktisan penggunaan melalui gadget, keefektifan melalui pengolahan skor menggunakan Gradebook, dan terintegrasi pada aplikasi LaTeX sehingga dapat memudahkan guru membuat soal matematika yang melibatkan rumus. Selain itu, pelatihan Edmodo dapat dilakukan secara online dengan cara pengiriman tugas guru berupa pembuatan kuis maupun gradebook yang hasilnya dapat diakses secara langsung melalui kelas pelatihan pada aplikasi Edmodo.

\section{UCAPAN TERIMA KASIH}

Pelatihan Edmodo ini merupakan kegiatan pengabdian kepada masyarakat yang didanai oleh Direktorat Penelitian dan Pengabdian kepada Masyarakat Universitas Muhammadiyah Malang Tahun 2018.

\section{DAFTAR PUSTAKA}

Abou El-Seoud, S., Seddiek, N., TajEddin, I., Ghenghesh, P., Nosseir, A., \& El-Khouly, M. (2014). E-Learning and Students' Motivation: A Research Study on the Effect of E-Learning on Higher Education. International Journal of Emerging Technologies in Learning (IJET), 9(4).

Adzobu, N. (2014). Design, Use and Evaluation of E-Learning Platforms: Experiences and Perspectives of a Practitioner from the Developing World 
Siti Khoiruli Ummah. Pelatihan Pembuatan E-Learning Sebagai ...

Studying in the Developed World. Informatics, 1(2).

Al-Said, K. M. (2015). [JOURNAL BI] Students perceptions of edmodo and mobile learning and their real barriers towards them. Turkish Online Journal of Educational Technology, 14(2).

Ali, Z. (2015). A Case Study of Tertiary Students " Experiences Using Edmodo in Language Learning. International Journal of Language Education and Applied Linguistics, 02,

Batsila, M., Tsihouridis, C., \& Vavougios, D. (2014). Entering the web-2 edmodo world to support learning: Tracing teachers' opinion after using it in their classes. International Journal of Emerging Technologies in Learning, 9(1).

Bobo, M. (2018). Jurnal Bidang Pendidikan Dasar (JBPD), 2(1).

Ekici, D. I. (2017). The Use of Edmodo in Creating an Online Learning Community of Practice for Learning to Teach Science. Malaysian Online Journal of Educational Sciences, 5(2).

Hadullo, K., Oboko, R., \& Omwenga, E. (2017). A model for evaluating e-learning systems quality in higher education in developing countries. International Journal of Education and Development Using Information and Communication Technology, 13(2).

Hassan, H., Hassan, F., Omar, N. D. @, Zakaria, Z., \& Nor, W. A. W. M. (2012). Evaluating Mathematics e-Learning Materials: Do
Evaluators Agree with Distance Learners? Procedia - Social and Behavioral Sciences.

Kurniasih, R., Sujadi, I., \& Subanti, S. (2016). Pengembangan Bahan Ajar Dengan Edmodo Untuk Meningkatkan Level Berpikir Probabilistik Siswa Kelas Viii Smp Negeri 12 Surakarta. Jurnal Elektrik Pembelajaran Matematika, 4(10).

Matthew, D., Joro, I. D., \& Manasseh, H. (2015). The Role of Information Communication Technology in Nigeria Educational System, 2(2).

Nasrullah, A., Tinggi, P., \& Bangsa B. (2017). Efektivitas Penggunaan Media Edmodo Pada, 2, 1-10. Pgri, U. (n.d.). No Title.

Roberts, R. (2009). Video Conferencing in Distance Learning: A New Zealand Schools ' Perspective, 13(1).

Technology, C. (2012). Factors influencing teachers ' adoption and integration of information and communication technology into teaching: A review of the literature Charles BuabengAndoh, 8(1).

Thakur, V. (2017). ICT Transforming Teaching \& Learning System, (July 2016). https://doi.org/10.18535/ijsrm/v 4i7.02.

Yengin, I., Karahoca, D., Karahoca, A., \& Yücel, A. (2010). Roles of teachers in e-learning: How to engage students \& how to get free e-learning and the future. Procedia - Social and Behavioral Sciences, 2(2). 